Supporting Information

\title{
Microscopic structural evolution during ultrastable metallic glass formation
}

Peng Luo ${ }^{1 *}$, Fan Zhu' ${ }^{2}$, Yu-Miao Lv ${ }^{1}$, Zhen Lu$^{3}$, Lai-Quan Shen ${ }^{1}$, Rui Zhao ${ }^{1}$, Yi-Tao Sun ${ }^{1}$, Gavin B. M. Vaughan $^{4}$, Marco di Michiel ${ }^{4}$, Beatrice Ruta ${ }^{4,5}$, Hai-Yang Bai ${ }^{16,7 *}$, and Wei-Hua Wang ${ }^{1,6,7}$

${ }^{1}$ Institute of Physics, Chinese Academy of Sciences, Beijing 100190, China

${ }^{2}$ State Key Laboratory of Metal Matrix Composites, School of Materials Science and Engineering, Shanghai Jiao Tong University, Shanghai 200030, China

${ }^{3}$ World Premier International Research Centers Initiative (WPI), Advanced Institute for Materials Research, Tohoku University, Sendai, Japan

${ }^{4}$ ESRF-The European Synchrotron, CS 40220, 38043 Grenoble Cedex 9, France

${ }^{5}$ Univ Lyon, Université Claude Bernard Lyon 1, CNRS, Institut Lumière Matière, Villeurbanne, France ${ }^{6}$ Songshan Lake Materials Laboratory, Dongguan, Guangdong, 523808, China

${ }^{7}$ Center of Materials Science and Optoelectronics Engineering, University of Chinese Academy of Sciences, 100049 Beijing, China

*E-mail: pengluo@iphy.ac.cn (P.L.); hybai@iphy.ac.cn (H.Y.B.)

\section{This Supporting Information includes the following contents:}

In-house XRD characterizations (Figure S1)

AFM characterizations (Figure S2)

Typical sequential nanoindentation results (Figure S3)

Derivatives of the heat flow (Figure S4)

Estimation of the enthalpy change (Figure S5)

Interatomic bond length, weight factor, and heat of mixing (Table S1) 


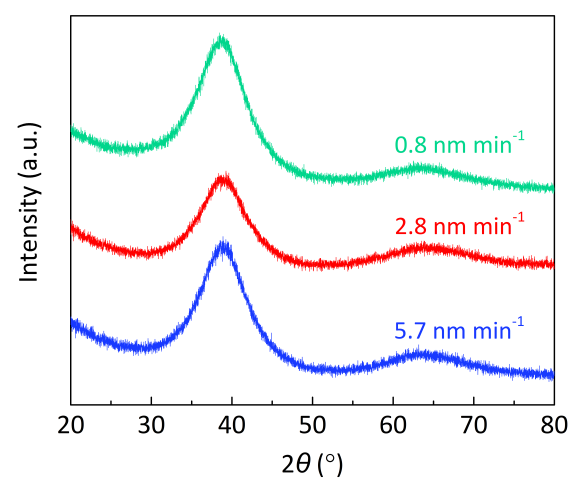

Figure S1. In-house $\mathrm{XRD}$ characterizations for $\mathrm{Zr}_{46} \mathrm{Cu}_{46} \mathrm{Al}_{8} \mathrm{MG}$ films prepared at different deposition rates.
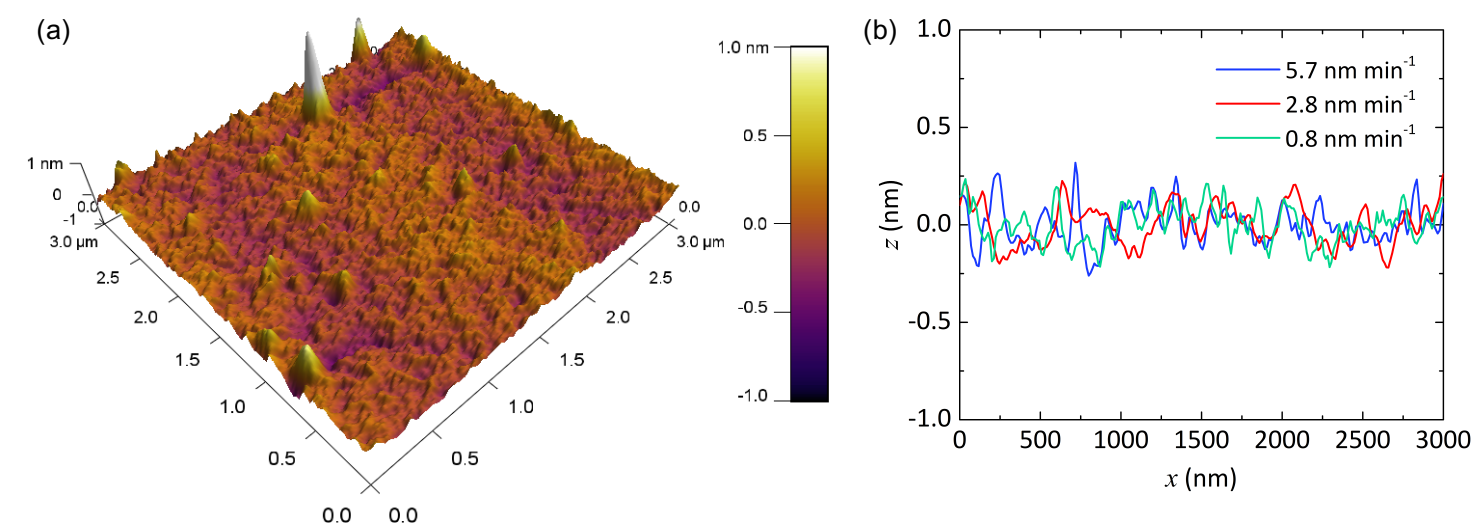

Figure S2. (a) Example of surface topography of $\mathrm{Zr}_{46} \mathrm{Cu}_{46} \mathrm{Al}_{8} \mathrm{MG}$ films deposited at $2.8 \mathrm{~nm} \mathrm{~min}{ }^{-1}$ measured with atomic force microscopy (AFM, Bruker Dimension Edge). (b) Representative height scan profiles for samples obtained at different deposition rates. These samples show a root-meansquare surface roughness of $\approx 0.15 \mathrm{~nm}$. 

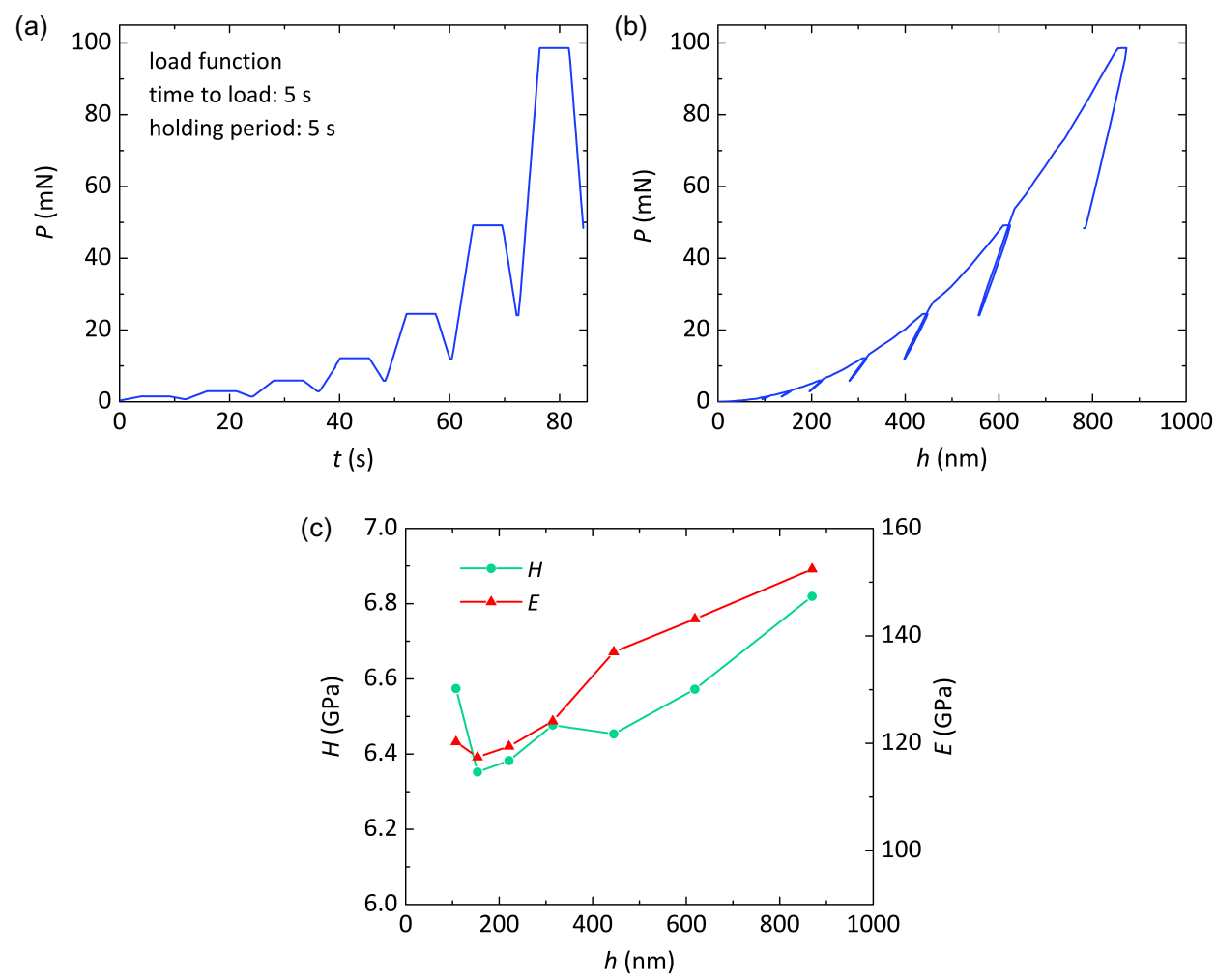

Figure S3. Typical sequential nanoindentation results from a $2 \mu \mathrm{m}$ thick $\mathrm{Zr}_{46} \mathrm{Cu}_{46} \mathrm{Al}_{8} \mathrm{MG}$ films deposited on $\operatorname{Si}(001)$ substrate at $5.7 \mathrm{~nm} \mathrm{~min}^{-1}$ : (a) load-time $(P-t)$, (b) load-depth $(P-h)$ curves, (c) hardness $(H)$, and elastic modulus $(E)$ as a function of the contact depth. At small contact depth $(h<150 \mathrm{~nm})$, a decrease of hardness and modulus associated with indentation size effect can be observed, and substrate effect arises when the contact depth is larger than $\sim 200 \mathrm{~nm}$ where the hardness and modulus increase with further indentation. 


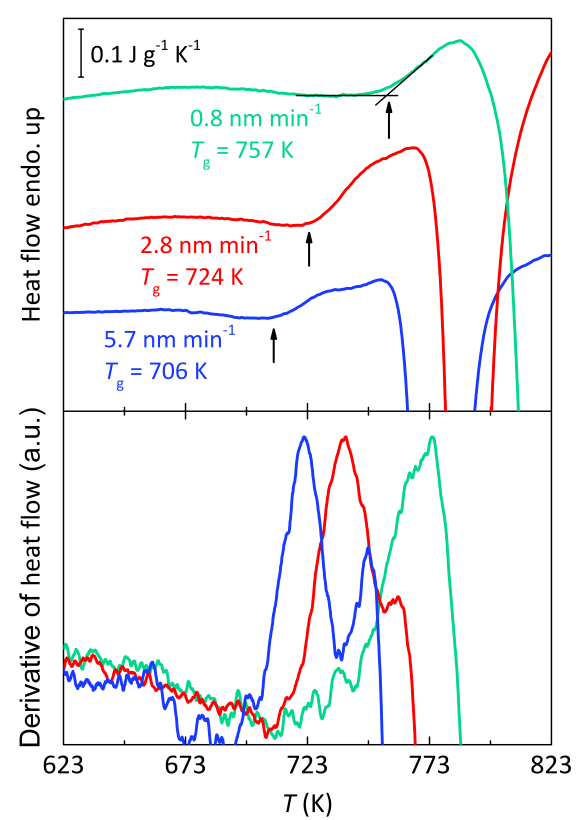

Figure S4. Derivatives (lower panel) of the heat flow data measured at $20 \mathrm{~K} \mathrm{~min}^{-1}$ for $\mathrm{Zr}_{46} \mathrm{Cu}_{46} \mathrm{Al}_{8}$ MGs deposited at different rates (upper panel). The MG deposited at $5.7 \mathrm{~nm} \mathrm{~min}^{-1}$ shows two peaks, the second peak results from the inflection between $T_{\mathrm{g}}$ and the crystallization temperature. The MG deposited at $2.8 \mathrm{~nm} \mathrm{~min}^{-1}$ also shows two peaks, while the second one is much weaker than that of the $5.7 \mathrm{~nm} \mathrm{~min}{ }^{-1}$ deposited MG. The $0.8 \mathrm{~nm} \mathrm{~min}{ }^{-1}$ deposited MG shows only one peak. 

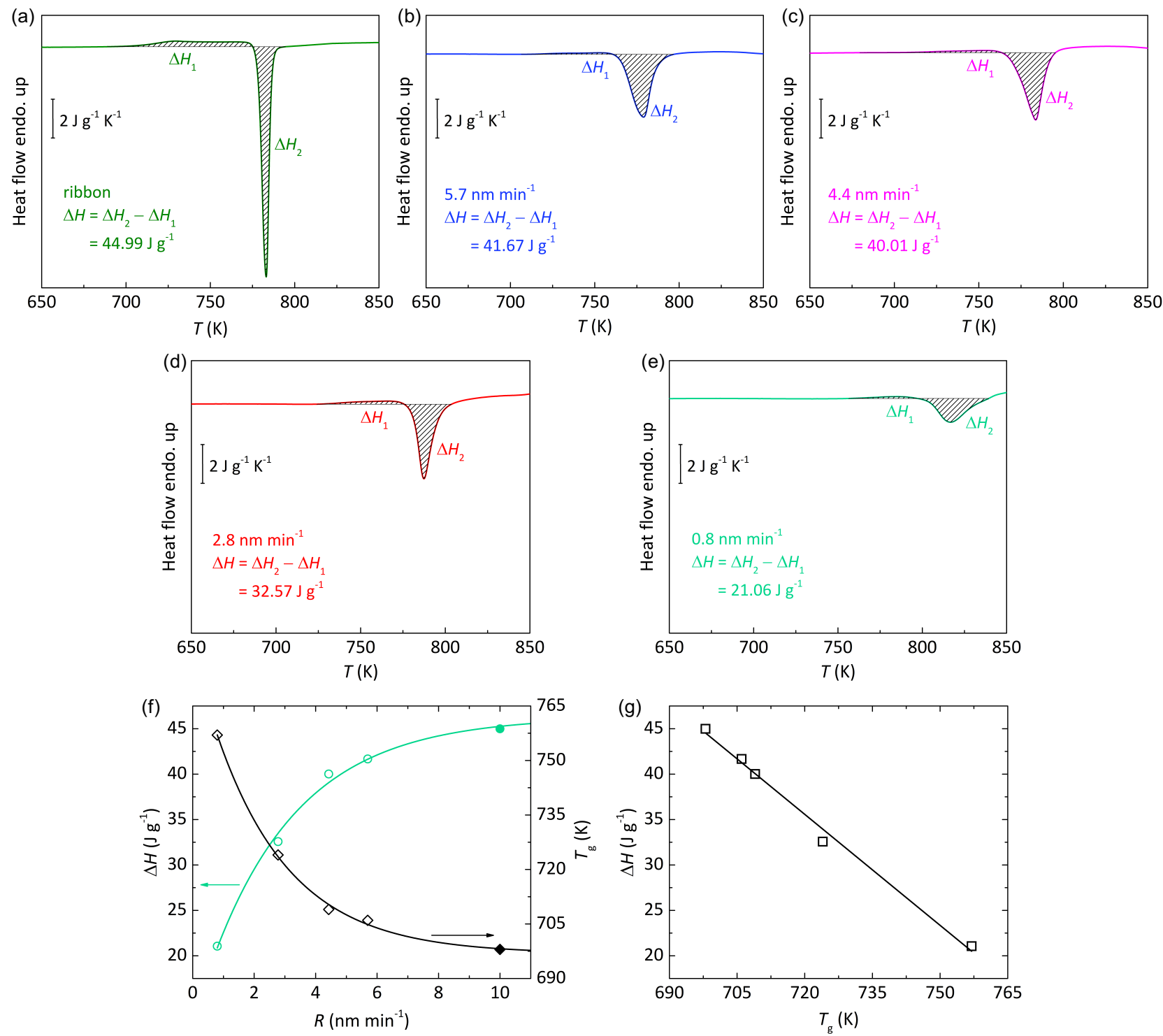

Figure S5. (a-e) DSC up-scans at $20 \mathrm{~K} \mathrm{~min}^{-1}$ for $\mathrm{Zr}_{46} \mathrm{Cu}_{46} \mathrm{Al}_{8} \mathrm{MGs}$ prepared by liquid-quenching (a) and by vapor-deposition at $5.7 \mathrm{~nm} \mathrm{~min}^{-1}$ (b), $4.4 \mathrm{~nm} \mathrm{~min}^{-1}$ (c), $2.8 \mathrm{~nm} \mathrm{~min}^{-1}$ (d) and $0.8 \mathrm{~nm} \mathrm{~min}-1$ (e). The shadow regions denote the integration range for the evaluation of the total amount of enthalpy change from glassy state to supercooled liquid, and finally to fully crystallized state, $\Delta H=\Delta H_{2}-$ $\Delta H_{1}$, where $\Delta H_{1}$ and $\Delta H_{2}$ represent, respectively, the endotherm at supercooled liquid region and the exotherm associated with crystallization. (f) $\Delta H$ (circles) and $T_{\mathrm{g}}$ (diamonds) as a function of deposition rate $(R)$, solid symbols represent liquid-quenched MG ribbon. The lines are exponential fits. Continuous decrease of $\Delta H$ and increase of $T_{\mathrm{g}}$ with decreased deposition rate is well visible. (g) $\Delta H$ as a function of $T_{\mathrm{g}}$, the line is a linear fit. 
Table S1. Interatomic bond length $\left(r_{\mathrm{ij}}\right),{ }^{1}$ weight factor $\left(W_{\mathrm{ij}}\right)$ and heat of mixing $\left(\Delta H_{\mathrm{ij}}{ }^{\mathrm{mix}}\right)^{2}$ of atomic pairs in the $\mathrm{Zr}_{46} \mathrm{Cu}_{46} \mathrm{Al}_{8}$ metallic glass.

\begin{tabular}{|c|c|c|c|}
\hline $\mathrm{i}-\mathrm{j}$ & $r_{\mathrm{ij}}(\AA)$ & $W_{\mathrm{ij}}$ & $\Delta H_{\mathrm{ij}}{ }^{\mathrm{mix}}\left(\mathrm{kJ} \mathrm{mol}^{-1}\right)$ \\
\hline $\mathrm{Zr}-\mathrm{Zr}$ & 3.20 & 0.316 & - \\
\hline $\mathrm{Zr}-\mathrm{Cu}$ & 2.88 & 0.457 & -23 \\
\hline $\mathrm{Zr}-\mathrm{Al}$ & 3.03 & 0.036 & -44 \\
\hline $\mathrm{Cu}-\mathrm{Cu}$ & 2.56 & 0.165 & - \\
\hline $\mathrm{Cu}-\mathrm{Al}$ & 2.71 & 0.026 & -1 \\
\hline $\mathrm{Al}-\mathrm{Al}$ & 2.86 & 0.001 & - \\
\hline
\end{tabular}

\section{References}

(1) Jiang, Q. K.; Wang, X. D.; Nie, X. P.; Zhang, G. Q.; Ma, H.; Fecht, H. J.; Bendnarcik, J.; Franz, H.; Liu, Y. G.; Cao, Q. P.; Jiang, J. Z. Zr-(Cu,Ag)-Al Bulk Metallic Glasses. Acta Mater. 2008, $56(8), 1785-1796$.

(2) Takeuchi, A.; Inoue, A. Classification of Bulk Metallic Glasses by Atomic Size Difference, Heat of Mixing and Period of Constituent Elements and Its Application to Characterization of the Main Alloying Element. Mater. Trans. 2005, 46 (12), 2817-2829. 